\title{
21. The Effects of Dorsal Root Stimulation on the Release of Endogenous Glutamate from the Frog Spinal Cord
}

\author{
By Akira Takeuchi, Kayoko Onodera, and Reiko KaWAgoe \\ Department of Physiology, School of Medicine, \\ Juntendo University, Hongo, Tokyo 113 \\ (Communicated by Yasuji Katsuki, M. J. A., April 12, 1983)
}

Glutamic acid and substance $\mathrm{P}$ are leading candidates among putative transmitters that have been proposed for the primary afferent pathways in the spinal cord.1,2) However, no firm conclusion has been reached for the transmitter role of these substances. Substance $\mathrm{P}$ is several times more effective than L-glutamate in depolarizing motoneurones, but its action is slow compared to the natural transmitter. ${ }^{3)}$ Although the action of glutamate is rapid, the release of this substance has not been observed in the spinal cord following dorsal root stimulation. ${ }^{4)}$ Recent studies in the crayfish neuromuscular junction have provided strong evidence that glutamate is released and acts as the excitatory transmitter.5),6) In the present experiments, therefore, the possibility as to whether the endogenous glutamate was released from the spinal cord following dorsal stimulation was explored.

Methods. The spinal cord and attached roots were carefully removed from bullfrogs (Rana catesbiana) in ice-cold Ringer's solution bubbled with $\mathrm{O}_{2}$ gas (with $5 \% \mathrm{CO}_{2}$ ). Experiments were undertaken on two types of preparations.

a) The hemisected cord. The preparation was placed in $200 \mu \mathrm{l}$ of the solution, which was collected every $10 \mathrm{~min}$ for the amino analysis.

b) The intra-arterially perfused spinal cord. ${ }^{7}$ ) The preparation was placed in a bath and a glass cannula was inserted into the anterior spinal artery, and oxygenated Ringer solution was perfused at a rate of $300 \mu 1 / 10 \mathrm{~min}$. The outflow from the vein was stored in the bath and collected every $10 \mathrm{~min}$.

The bath solution was bubbled with $\mathrm{O}_{2}$ gas and cooled to $7-9^{\circ} \mathrm{C}$ to prevent the uptake of amino acids. The Ringer's solution used was $(\mathrm{mM}): \mathrm{NaCl} 115 ; \mathrm{KCl} 2.0 ; \mathrm{CaCl}_{2} 2.0 ; \mathrm{pH}$ was adjusted to 7.2 by HEPES.

The 8th ventral root was led into a separate compartment through a hole made on rubber film and the ventral root potential 
(VRP) was recorded with a pair of calomel-wick electrodes. Dorsal roots (7-9th) were introduced into another compartment and placed on a pair of silver electrodes for nerve stimulation. To ensure a leakproof separation of the compartment, all holes through which roots were led were coated with petroleum jelly. A train of 10 or 20 stimuli was applied every sec and the strength of the stimuli was adjusted to juxtamaximal for fast VRP.

The concentrations of glutamate and aspartate in the solution were measured by mass fragmentography using a gas chromatographmass spectrometer (GC-MS) (Finnigan Type 4000). ${ }^{6}$ ) A negative ion detector was used for the mass fragmentography (negative ionchemical ionization). ${ }^{8)}$ With this method glutamate and aspartate of less than 1 pmole in sample were measured.

Results. The results shown in Fig. 1 were obtained from an intra-arterially perfused spinal cord at $8^{\circ} \mathrm{C}$. The filled columns represent glutamate (Glu) and aspartate (Asp) contents during $10 \mathrm{~min}$ resting period. The resting release of glutamate was relatively large, being 100-200 pmole per sample. A train of 10 stimuli was applied every sec to dorsal roots for $9 \mathrm{~min}$ and it produced VRP of about $200 \mu \mathrm{V}$, as shown at the top of Fig. 1A. The amino acid content during nerve stimulation is indicated by the hatched columns. The glutamate efflux during dorsal root stimulation was increased by
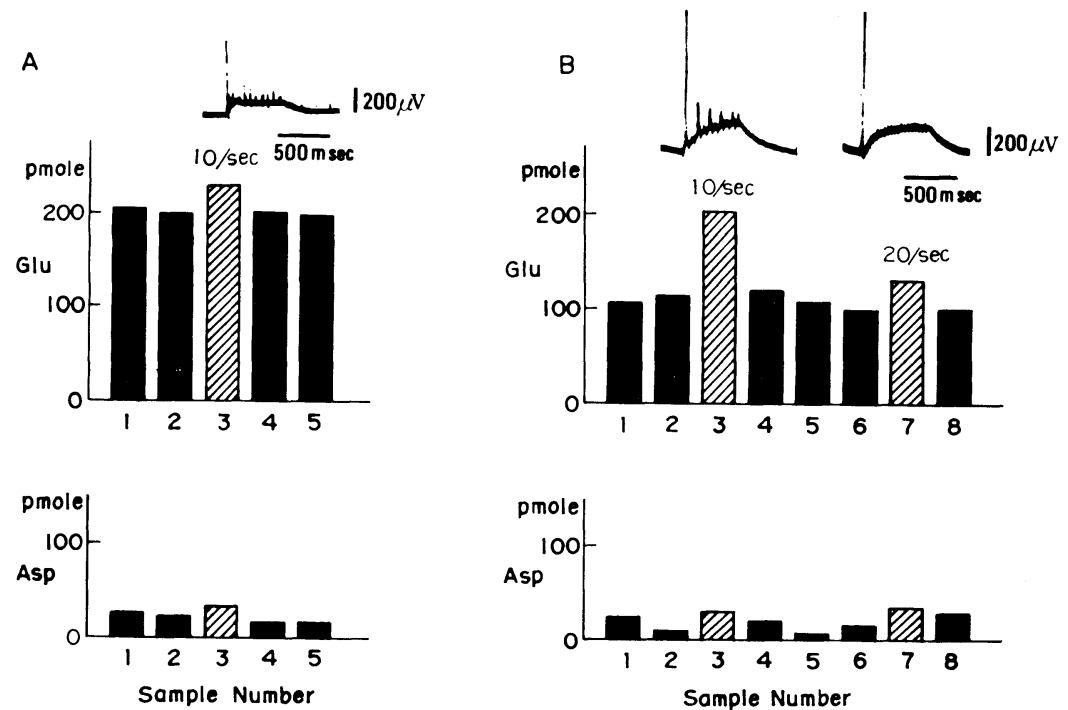

Fig. 1. The effects of dorsal root stimulation on glutamate and aspartate release from intra-arterially perfused spinal cords. Each column represents the release during a collection period of $10 \mathrm{~min}$. The solid columns are resting release and the hatched columns are those during dorsal root stimulation. Sample records of VRP are shown at the top. A and B were obtained from two different spinal cords. 
about 30 pmole in excess of the background. Fig. 1B shows another example. Dorsal root stimulation at $10 / \mathrm{sec}$ increased glutamate efflux by about 80 pmole, whereas the second series of nerve stimuli at 20 /sec was not very effective, with the increase in glutamate efflux being about 30 pmole. The background efflux of glutamate varied from preparation to preparation $(118.67 \pm 6.47$ pmole (mean \pm S.E.) $(n=46))$ and the increase in the glutamate efflux by dorsal root stimulation was small. However, when the glutamate efflux during nerve stimulation was compared with the mean value of the controls before and after nerve stimulation, a significant increase in the glutamate efflux was found in excess of the mean control release $(15.78 \pm 6.79, \mathrm{n}=13) \quad(\mathrm{P}<0.05$, paired $t$ test $)$.

The resting release of aspartate (Asp) was several times smaller than that of glutamate as shown in Fig. 1, the average value being $21.10 \pm 1.01$ pmole $(n=46)$. The dorsal root stimulation produced a small but significant increase in aspartate, the net increase being $3.61 \pm 1.93$ pmole $(\mathrm{n}=13) \quad(\mathrm{P}<0.1)$.

In the intra-arterially perfused preparations, the diffusion of amino acids into perfusate may be restricted by the blood-brain barriers. Therefore, a more conventional hemisected preparation was also used (Fig. 2). The resting release of glutamate was usually smaller than that observed in the intra-arterially perfused preparations. This may be partly attributed to the small volume of the hemisected spinal cords compared to the intra-arterially perfused preparations. The background release of glutamate averaged $31.21 \pm$

A
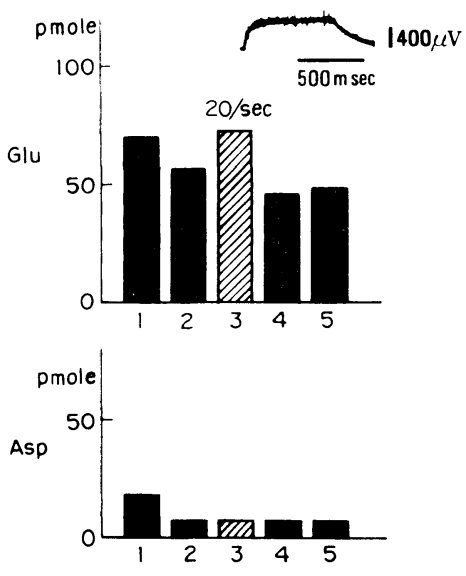

B
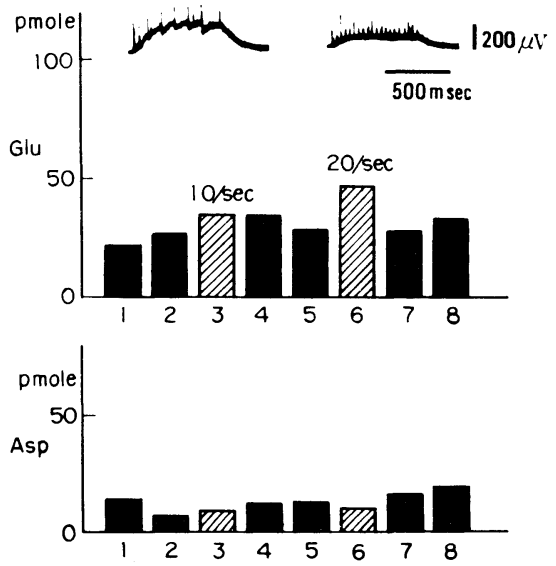

Sample Number

Fig. 2. The effects of dorsal root stimulation on glutamate and aspartate release from hemisected spinal cords. A and B were obtained from two different preparations. 
3.42 pmole $(n=19)$. The net increase of glutamate efflux brought about by dorsal root stimulation at $20 / \mathrm{sec}$ was $16.35 \pm 6.62$ pmole $(\mathrm{n}=5, \mathrm{P}<0.1)$. In this preparation the dorsal root stimulation produced an increase in the aspartate efflux on some occasions, but its value was variable and statistically not significant.

The effects of $\mathrm{Ca}$ on the glutamate and aspartate release were tested using the hemisected spinal cords. The Ca concentration of Ringer's solution was decreased to $0.1 \mathrm{mM}$ by replacing $\mathrm{Ca}$ with $\mathrm{Mg}$. When the spinal cord was soaked in the low $\mathrm{Ca}$, high $\mathrm{Mg}$ solution for $30 \mathrm{~min}$, the amplitude of VRP was decreased in most cases to less than $50 \mu \mathrm{V}$. The net release of glutamate produced by dorsal root stimulation at $10 / \mathrm{sec}$ was significantly smaller in low Ca solution than that in the control (Table I). The net release of aspartate also showed a tendency to decrease in the low Ca solution, but this was statistically not significant.

Table I. The effects of low Ca on net release of glutamate and aspartate (10/sec stimulation) (mean \pm S.E. pmole)

\begin{tabular}{ccc}
\hline & Control & low Ca \\
\hline Glutamte & $13.44 \pm 4.89$ & $1.64 \pm 3.14 \%$ \\
& $(\mathrm{n}=11)$ & $(\mathrm{n}=7)$ \\
Aspartate & $11.24 \pm 6.31$ & $2.34 \pm 1.20$ \\
& $(\mathrm{n}=11)$ & $(\mathrm{n}=7)$ \\
\hline
\end{tabular}

* $\mathrm{P}<0.1$ compared with control.

Discussion. The present experiments constitute the first demonstration that the dorsal root stimulation produced a calcium dependent release of endogenous glutamate from the spinal cord. Since the stimulus strength was adjusted to juxtamaximal in producing VRP, the primary afferents of larger sizes may be the major source of glutamate release. The contribution of aspartate was relatively small, but it might also have been acting as the transmitter in some parts of the spinal cord, e.g. the interneurones, because a significant release was found in the intra-arterially perfused preparations.

Acknowledgements. We would like to thank Dr. K. Murayama, Ms. R. Mineki and N. Shindo of the Central Laboratory of Medical Sciences, Juntendo University for their help in the amino acid analysis. These experiments were supported in part by grants from the Ministry of Education, Science and Culture, Japan and from Takeda Science Foundation.

\section{References}

1) Otsuka, M., and Takahashi, T.: Ann. Rev. Pharmacol. Toxicol., 17, 425-439 (1977). 
2) Krnjevic, K.: Handbook of Physiology, The Nervous System II. American Physiological Society, Bethesda, Maryland, pp. 107-154 (1981).

3) Nicoll, R. A.: Neuroscience Symposia. vol. I (eds. Ferrendelli, J. A., McEwen, B. S., and Snyder, S. H.). Society for Neuroscience, Bethesda, Maryland pp. 99-122 (1975).

4) Roberts, P. J., and Mitchel, J. F.: J. Neurochem., 19, 2473-2481 (1972).

5) Kawagoe, R., Onodera, K., and Takeuchi, A.: J. Physiol., 312, 225-236 (1981).

6) — : ibid., 322, 529-539 (1982).

7) Kudo, Y.: Prog. Neurobiol., 11, 1-76 (1978).

8) Hunt, D. F., and Crow, F. W.: Anal. Chem., 50, 1781-1784 (1978). 